\title{
Replacing a Hospital Information System: an Example of a Real-World Case Study
}

\author{
Klaas Sikkel $^{(1)}$, Ton A.M. Spil ${ }^{(2)}$, Rob L. W. van de Weg ${ }^{(1)}$ \\ ${ }^{(1)}$ Faculty of Computer Science \\ ${ }^{(2)}$ Faculty of Technology and Management, \\ University of Twente, \\ PO Box 217, \\ 7500 AE Enschede, the Netherlands \\ \{sikkel, vandeweg\}@cs.utwente.nl \\ a.a.m.spil@sms.utwente.nl
}

\begin{abstract}
Real-world case studies are important to complement the academic skills and knowledge acquired by computer science students. In this paper we relate our experiences with a course specifically designed to address this issue. The objectives of the course are threefold: to train management and communication skills, to integrate and apply knowledge gained at different previous courses, and to learn by experience the difference between a real-world problem and a textbook problem. Students' evaluations show that the objectives of the course are met and that it is regarded as very useful. We found that the three objectives mutually reinforce each other, which is a decisive factor for the success of the course.
\end{abstract}

\section{Introduction}

Software industry in our country used to complain that academically trained software engineers are indeed very academic. Rooted in a tradition in which computer science is strongly linked with mathematics, and software engineering is a subdiscipline of computer science, we used to deliver highly skilled scientific programmers, who could generate suitable implementations for arbitrarily complex problem descriptions, but with little feeling for how software systems function in real organizations.

The complaint that engineers graduating from universities have not acquired the professional skills needed in industry is heard in other countries as well [1,2]. In the Netherlands it became a public issue ten years ago, when a group of major industries and banks announced plans to set up a private university, offering postgraduate courses to their employees, so as to make up for the perceived deficiencies of the universities. In a country in which all higher education is publicly financed, this was an unusual and provocative initiative. 
The industry university never was realized, but the initiative did rouse a public discussion around the function and quality of higher education.

For other reasons the academic curricula in the Netherlands have been subject to a number of changes over the last fifteen years. Declining funding called for more efficiency, viz., reducing the time needed for academic studies. The curriculum for a Master's degree currently has a nominal length of four or five years (after secondary school - in the Netherlands there is generally no division between undergraduate and graduate studies). As a result of shortening the studies, there was a trend to offer a more varied spectrum of carefully tailored curricula.

One of these new curricula at the University of Twente is called "Business Information Technology" (BIT) [12]. It integrates computer science and management science and has been set up in consultation with industry in order to address the problem mentioned above. The BIT programme started in 1993 and has a yearly influx of 40-60 students. It has a length of four years; students obtain a Master's degree at the age of 22-23.

It is strongly felt that Business Information Technology should not be merely a collection of courses from the participating faculties, Computer Science and Technology \& Management, but should offer a truly integrated curriculum, delivering engineers trained to think beyond the narrow boundaries of a single discipline. To this end, the curriculum contains a series of project-based courses, in which real-world situations are simulated as closely as possible.

The benefits of real-word exercises are known [4,13], the problem is how to achieve this within the setting of a university curriculum. In this paper we describe the set-up and our experiences of one such project-based course, the so-called BIT integration project, at the end of the first year.

\subsection{The BIT integration project}

The project centers around a case study of an IT problem in a large, complex organization. The objectives of the project are threefold:

- to learn to apply and integrate the knowledge gained in different courses throughout the first year;

- to train the skills needed to work in project teams;

- to learn by experience the difference between textbook problems and real-world problems.

We regard it as very important that the case study is taken from reality. There is a sharp contrast between real case studies and constructed exercises. A real problem is complex, fuzzy, and embedded in a particular environment. There is probably not a single best solution to the problem. Furthermore, in principle, all matters arising and questions not anticipated in the project description can be addressed if there is a need for more detailed information. In our project, contact with the organization is moderated, however. Except for an excursion to the organization, students should address further questions about the case study to the supervisors, in order to avoid burdening of key persons in the organization.

The project is done in a single week of full-time work, after an orientation phase spread out over the preceding six weeks. Obviously, students cannot do in a week what a professional team did in more than a year; the size of the project is a limiting factor. In a regular course, say, a software engineering course, there is much to say for cutting down on problem complexity and doing a compete life cycle on a toy project; it is the SE life cycle that should be studied, and the example has to fit the course. In the integration project, on the contrary, it is of prime importance to have a case that is as realistic as possible. As a consequence, only a few bits of 
the real project work are carried out, but the fuzziness of a problem in a complex environment is retained.

After 5 years of experience, the project has been thoroughly overhauled and a new case study has been set up. The 1998 case study was situated in a large hospital, which we will call "Medinet" here.

Medinet is faced with a problem: the supplier of the hospital information system (HIS) has been overtaken and the new supplier will end the service contract. A new HIS has to be installed and to be integrated with more than a dozen heterogeneous peripheral systems. What are the requirements for a new system, who could supply it, and how is a conversion from the old to the new system to be organized?

Before we discuss the set-up of this project in more detail, we have a closer look at the background of the case study.

\section{The Hospital Information System at Medinet}

Medinet is a large regional hospital (1100 beds, more than 3000 employees). It was founded in 1988 as a merger of three local hospitals and two outpatient facilities. In a major reorganization, the hospital was transformed from a functional structure into a patient-oriented structure, in which the medical specialists have a central position. $60 \%$ of the employees are clustered around the primary processes (diagnosis, treatment, care). In addition, the organization comprises a medical technical center (25\%) and a division for general support facilities $(15 \%)$. The medical divisions are organized according to geographical location.

In the early 1990's, in the fashion of those days, the IT infrastructure was based around a monolithic HIS to which dumb terminals were connected via a network of terminal concentrators. A range of separate systems in the various parts of the hospital operated standalone or communicated with the HIS through gateways. In order to allow a better integration of peripheral systems, it was decided to move to a more open network infrastructure. This transformation was well underway, but not yet completed, when, in February 1996, Medinet was notified that the service contract would expire at the end of 1997.

Thus, at the point in time at which the case study is situated, the hospital's IT infrastructure is in a transitory state, guided by a plan that, due to the unexpected demise of the HIS, has become obsolete before it was realized. For a real infrastructure in a real organization, there is nothing surprising or unusual about such a state of affairs. But this is the type of situation that distinguishes the textbook example from the real-life case. Figure 1 sketches a (simplified) picture of Medinet's network topology at the start of the project; the configuration only makes sense if the history of the environment and the ongoing reorganization are taken into account.

Figure 2 gives an impression of the variety of information systems at Medinet. Central is the core HIS. It consists of three subsystems: patient registration, financial accounting, and a laboratory support system, with a central database. The core HIS is the part that has to be replaced. The other systems connecting to it can remain in the new situation, but might have to be adapted in order to exchange data with the system(s) replacing the core HIS. Figure 2 is taken from an original Medinet drawing and further details about these systems are not relevant here (the labels are unintelligible also to uninvolved Dutch speakers).

Some more details about the HIS conversion project at Medinet can be found in [11]. 


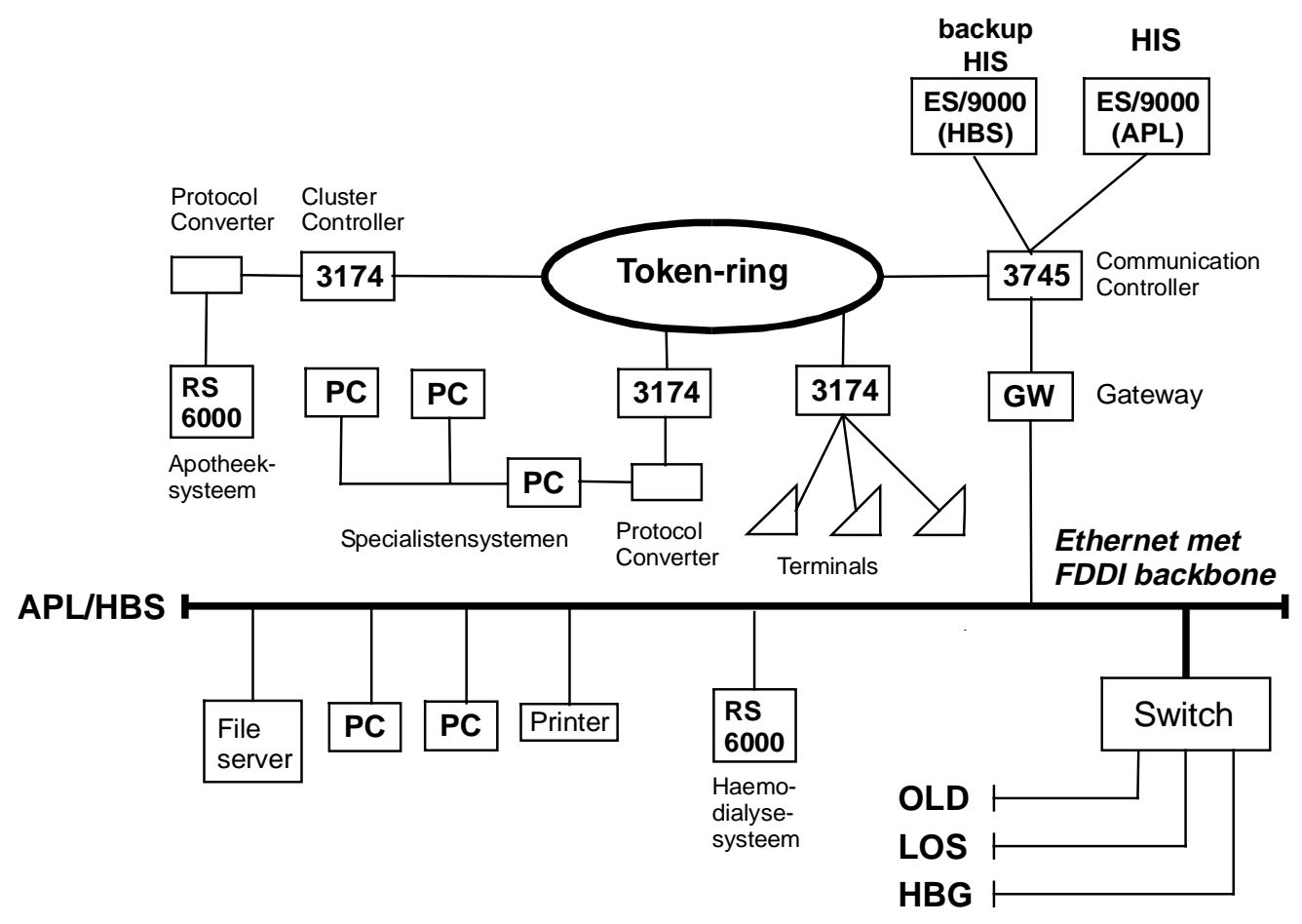

Figure 1: The network infrastructure at Medinet

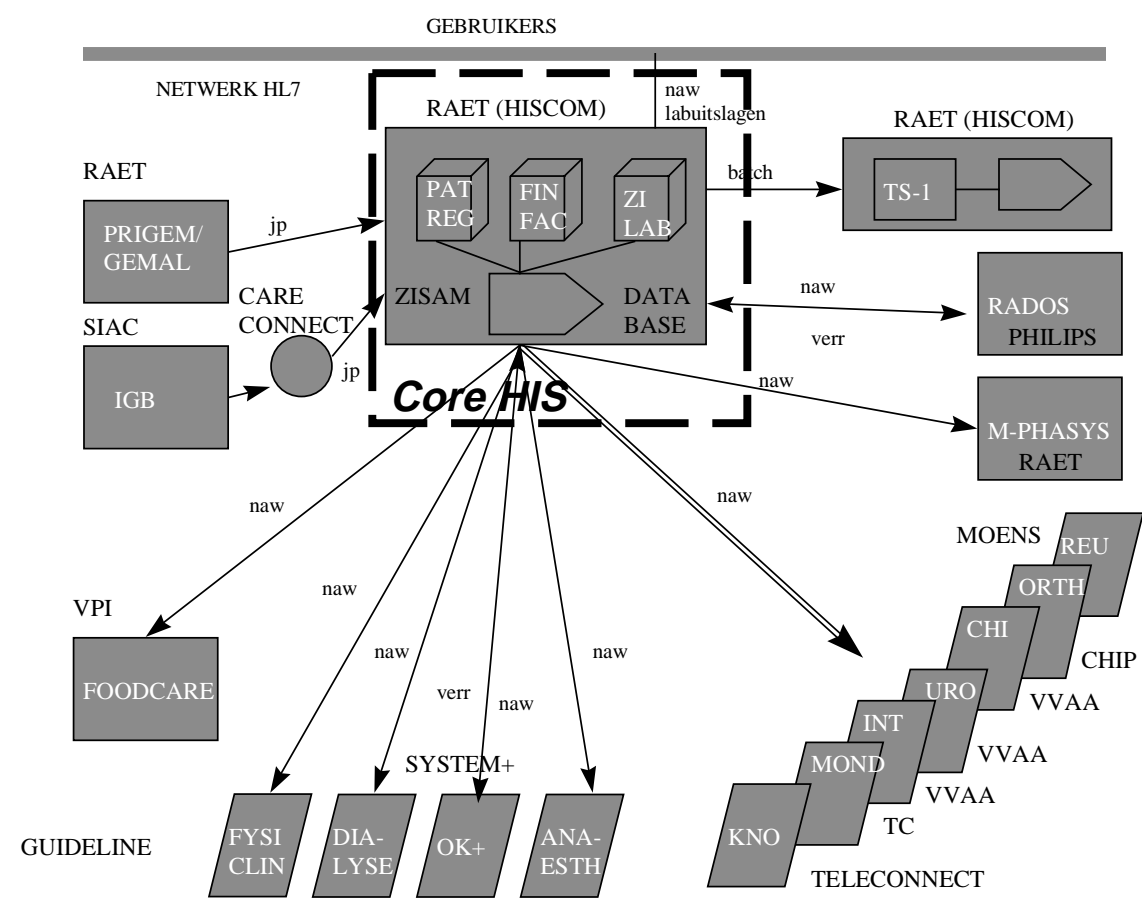

Figure 2: Information systems at Medinet 


\section{Set-up of the BIT integration project}

The real project is a single week of full-time work. It is the very last week of the first year, scheduled after the exams, so that the students can fully concentrate on the project. In order to prepare for the project, there is an introductory phase, spread over 6 weeks, in which several course modules serve to train management and communication skills, to re-activate the knowledge from previous courses and to acquire background knowledge about the IT situation in Medinet.

The nominal time allocated for the course is 160 hours of work, from a yearly total of 1680 , a figure prescribed by the Ministry of Education. The introductory phase accounts for 120 hours, the project week 40 hours. The actual time spent by the students does not differ much. There is little homework and most tasks are carried out real-time: after an introductory lecture the group starts working and the assignment has to be handed in the same day before 5:30 PM.

\subsection{The introductory phase}

The introductory phase consists of the following modules.

- Management and communication skills (60 hours). This course is roughly based on Quinn et al. [7]. Emphasis is on team building, project management, written and oral presentation.

- Business research (15 hours), in which students learn to state a research problem before they start working.

- Thematic exercises (30 hours) on business administration, information system design and computer networks, to re-activate what was learned in previous courses.

- An excursion to the Medinet hospital.

Most of the practical work in the introductory phase is in the form of group exercises, there are some individual exercises.

Various forms of group composition are discussed by Scott and Cross [9]. We compose the teams of 5-6 students more or less random, but if students have deficiencies in prerequisite knowledge they are not put together in one team. Team building is one of the subjects in the management skills module, therefore it is appropriate to start with teams in which most people have not yet worked together. In the evaluation, students said they were satisfied with the way the teams were composed. Teams remain the same throughout the project, unless a total breakdown occurs, but students are encouraged to rotate roles within the team. Designated roles are team coordinator and quality manager. Depending on the task, the quality manager should focus on product quality or on team quality.

In addition to activating knowledge and training new skills, the introductory phase supplies the students with substantial background knowledge of the Medinet case. The management module has an exercise in searching for information, in which students gather information about suppliers of hospital information systems, which is relevant for the project week. Similarly, the subjects of the thematic exercises are all taken from Medinet. Exercises cover the management structure and financial situation of the hospital, a process model for the patient administration, and the network infrastructure of the hospital.

The only exercise that was not based on Medinet was in the business research module - a new course unit introduced this year. The led to some critical remarks in the evaluation, and in 1999 the exercise is to be replaced.

Trivial as it may seem, it takes some quite some coordination effort to ensure that the modules in this course, for which different persons are responsible, are consistent with each 
other and with what is taught in half a dozen other courses. Due to the way in which our university is organized - every lecturer is responsible for his own courses and modules coherence across courses needs active maintenance.

The thematic exercises are classified according to subjects that students have studied in separate courses and formally serve to re-activate knowledge. Yet, in addition, there is an important shift in the way in which exercises are set up - paving the way from textbookoriented exercises to real-world problem solving. Consider, for example, an exercise in information systems design.

Earlier in the year, students have made exercises, describing the design of an information system by means of an object model, a functional model, and behavioral models. The problem is very precisely specified on a sheet of paper, containing all information that is needed to draw up the model. The objectives there are to learn to make such models and to learn to use a particular modeling technique. In the integration project, the objective of the thematic exercise is to capture the information needs in a precise specification. On the one hand, there is an abundant amount of information. Some of it is redundant, some of it is irrelevant, some of it is inconsistent. On the other hand, the information is vague and incomplete. The models were now used to detect inconsistency and incompleteness of the description of the present situation. Only at this stage the students came to formulate the questions needed to clarify the situation and improve the description of the information needs. For the students this was a totally new situation and, because of the unclarity, experienced by many as frustrating.

Furthermore, it is required that the model to be submitted fits on a single sheet of A4 paper. Hence the students were forced to focus on the most important aspects of the system. Less relevant details had to be aggregated or simply discarded. This is also very unusual in a university setting, where it is typically required that answers to exercises are precise and complete, and this is hard to do for the first time.

The value of having an essential model, rather than a complete model, becomes clear later on, during the project week, when consequences for the organization, feasible migration paths to a new situation and involved costs have to be discussed and presented in a management report. At that point it turns out that the essential model, drawn up in the introductory exercise, is indeed useful resource.

\subsection{The project week}

The case study is done in single week, in which students work full time on the project. Two major assignments have to be carried out. For each assignment, two days are allocated. Working real-time with tight deadlines is an essential part of the exercise. It forces the groups to properly plan the work. There is no time to get lost in too much detail; one must concentrate on the main issues in order to get the work finished. A written report has to be submitted at the deadline, the next morning a presentation is given to the customer (played by the project supervisors). The assignments are:

\section{Make a strategic choice for a new HIS and propose this to the management board of Medinet.}

This includes drawing up requirements for the system, establishing criteria to evaluate potential suppliers, and discussing feasible options in a memo to the board. A lot of material on the hospital, partly from the real project archive, is available to the students. Searching for possible suppliers has already been done in the management skills module. 


\section{Propose a decomposition of the HIS into subsystems and report this to the coordination team for the HIS conversion.}

It is important to get a decomposition early in the HIS conversion project, in order to clarify which subsystems have to be re-implemented and which subsystems can be carried over into the new system. One of the issues that has to be addressed is whether patient registration is to be centralized or decentralized in the new situation.

In order to further enhance the realistic character of the project, the teams are interrupted by an unscheduled event providing new information. During task 1, the group is requested to come and see the management board of Medinet (played by the project supervisors). The management board has received a confidential special offer from one of the larger HIS suppliers and seeks the immediate advice of the project team. During task 2 , the head of the radio-therapy section has heard rumors about a more centralized HIS and, in a meeting with the coordination team (supervisors) and project team (students) insists that the autonomy of his section is in no way impaired.

The written reports have to be handed in on Tuesday and Thursday at 5:30 PM for task 1 and 2, respectively. The next morning there are oral presentations. This is done in two parallel sessions; about five teams present their work to the supervisors (playing to be Medinet management) and discuss each other's presentations. In each session a best team is selected. The best teams give a second presentation at a plenary session on Friday afternoon. This time, the presentation is given to an expert panel of real specialists (the information manager of Medinet, who headed the conversion project team in 1996-7, a second member from the project team, and an external consultant who advised Medinet on these matters).

The presentation to the expert panel is in a way the true acid test - not for the students, but for the course set-up and the teachers' guidance - as these experts are intimately familiar with Medinet's IT situation. Moreover, they base their judgement on the quality of the delivered work on their experience with the real project, more than on the course material [10] that was compiled by the teachers. The panelists did probe the presenting teams for arguments to back up their statements and indeed they were quite impressed with their performance. In a debriefing conversation, the external consultant in the expert panel remarked that the presented work was of higher quality than the work of some of his colleagues, and the IT manager said he could very well use some of these guys at Medinet's IT department.

\subsection{Grading}

For most parts, including the project week, students get a team grade. Team grading is a controversial issue $[3,8]$. When a substantial part of the curriculum is in form of team assignments, one needs methods to distinguish between individual contributions. This is an issue at the faculty of Mechanical Engineering at the University of Twente [6], which has adapted the Aalborg University [5] approach to project-based education. At Business Information Technology we find team grades acceptable. Only $20 \%$ of the BIT curriculum is organized in projects and there is little risk that students will slip though on work performed by others. Moreover, the integration project, unlike other courses, is not used as a means of selection. While it is possible, in principle, that a team fails for the project, this has never happened. In former years there were a few cases of individual students failing the project; they were thrown out by their team and the supervisors agreed that this was justified.

With each assignment that is handed in, students are requested to write down the division of work. In extraordinary circumstances persons may get different marks according to their individual contribution. In 1998 this happened with one team (out of 9) for the first assignment 
in the project week. There had been serious trouble in the team, but after a meeting with the supervisors the team decided to stay together. This team actually made up for it during the second assignment, for which it scored the best result of all.

In the project week, which is $25 \%$ of the work but accounts for $40 \%$ of the grade, grading of the team's work is primarily based on their written reports. Contents and argumentation are the primary criteria for grading. Structure, coherence, and layout are to a lesser extent taken into account. Oral presentation can raise or lower the grade with one point (on a scale of 10).

\section{Discussion and conclusions}

We are convinced that this project is very useful indeed, although it is hard to quantify its value. The students get a first experience of the nature of a real-world IT problem and learn to apply academic skills and team skills in a nontrivial case study. Moreover, what has been learned here is followed up in other project-based courses in the second and third year of the BIT curriculum.

The project has been subject to the faculty's formal evaluation procedure several times. Such evaluations are based on students' assessments of whether the objectives of the course have been reached and are geared towards issues that can be improved. Invariably it comes out that the objectives are reached and, that the course is among the ones most liked by the students. To be fair, it has to be remarked that the faculty's evaluation procedure does not validate whether the objects of a course are the proper ones - but for the integration project there is little reason to worry - and whether the students have truly acquired the skills they think they have acquired.

The students' impression is that the case study is very realistic. Further evidence that this is so comes from the experts on the panel in the final session. They assess the quality of the best four teams' results (two for every assignment) from the context of the real project. This shows that the material presented to the students properly reflects the real case and, more importantly, that the quality of the delivered work is high.

One of the reasons we can do a complex real-world case study in the integration project is that is it not a course in any particular academic subject, like software engineering or information system design, in which students have to acquire textbook knowledge and skills. It is a separate required course unit, specifically designed for this purpose.

A suitable case study and good preparation are obviously prerequisite to make a project like this worthwhile. We are convinced, however, that the key success factor of the BIT integration project is the combination of three elements that reinforce each other: training of management and communication skills, re-activating and integrating knowledge gathered at other courses, and practicing these on a real-world problem. Looking at each of these activities in context, we observe the following.

- Management and communication skills. There is a huge difference between the first sessions in the introductory phase, in which students do an exercise in presentation, and report sessions in the project week, in which students present their own work. The latter presentations have substance, as the work they report on has substance. We may still comment on the form, but these presentations are a lot more professional than what we have seen only a few weeks before. The same holds for playing to be a team, in the first module, and being a team in the project week. On average, the quality of the work delivered within the short time frame can only have been achieved because the team did work as a professional team. 
- Integration of knowledge. Actively using and combining knowledge from different university courses is hard work. An efficient way - if not the only way - to achieve this, is to work on a task which makes sense and which requires these different kinds of knowledge in order to get solved. Moreover, the project week is set up in such a way that the team members must work on different tasks in order to get the work finished in time, but they also must share, discuss and integrate their findings in order to obtain a coherent result.

- Real-world cases. In order to dig into a real-world case that is not trivialized but retains its real-world characteristics, one does need a team with professional competences. The work done in the project week is of high professional quality, and this cannot result from enthusiasm alone. The skills needed to get the job done have been trained (and using these skills in the project helps to further internalize them). Fewer than three weeks before, the information system design exercise (partly overspecified, partly underspecified, and generally vague) was a hard experience for most students, as testified in the course evaluation. Yet the case study assignments in the project week were no less vague, but nobody thought this inappropriate, and the teams were now better prepared for it.

In sum, our experiences show that it is possible to cover real-world case studies in a limited time span, 160 hours of work. Our key to success in a rather compact course is to combining the three mentioned factors into an integrated project in which they reinforce each other.

\section{Acknowledgements}

We thank our colleagues Henk Kroon and Joke Oosterhuis and the Medinet information management staff for fruitful cooperation on this project, Diana Limburg, Rom Langerak and Ing Widya for providing input to the thematic exercises, and Roel Wieringa and Judy Bamberger for constructive feedback on earlier versions of this paper.

\section{References}

[1] P.J. Denning (1992). Educating a new engineer. Communications of the ACM 35(12), 82-97.

[2] J. Goldfinch, P. Laybourn, L. MacLeod, S. Stewart (1997). Improving Groupworking Skills in Undergraduates through Employer Involvement. Proc. Int. Conf. on Project work in University Studies, Roskilde, Denmark, September 1997, Vol. II, p. 112-121.

[3] H. Grunefeld (1997). Beoordelen en Toetsen van Projectonderwijs [Grading project-based education; in Dutch] OC-DOC 97-41, Educational Centre, University of Twente, Enschede, the Netherlands.

[4] J. Hartman and C.M. White (1990). "Real World" Skills vs. "School Taught" Skills for the Undergraduate Computer Major. SIGCSE Bulletin 22 (1) 216-218.

[5] F. Kjersdam and S. Enemark (1994). The Aalborg Experiment: Project Innovation in University Education. Aalborg University Press, Aalborg, Denmark.

[6] E. M.A. Peters and P.C. Powell. The effects of the introduction of a project-based curriculum in the Mechanical Engineering course at the University of Twente. Proc. Int. Conf. on Project work in University Studies, Roskilde, Denmark, September 1997, Vol. I, p. 193-203.

[7] R.E. Quinn, S.R. Faerman, M.P. Thompson, M.R. Grath (1994). Handbook of Management Skills, Academic Service (Dutch translation).

[8] C.C.H. Rosen (1996). Individual Assessment of Group Projects in Software Engineering: A Facilitated Peer Assessment Approach. $9^{\text {th }}$ Conference on Software Engineering Education, 6877. 
[9] T.J. Scott and J. Cross (1995). Team Selection Methods for Student Programming Projects. $8^{\text {th }}$ Conference on Software Engineering Education, 295-303.

[10] K. Sikkel, J. Oosterhuis-Geers, T. Spil, and H. Heerkens (1998). Handleiding integratieproject BIT [lecture notes BIT integration project; in Dutch]. Lecture Notes No. 439, University of Twente, Enschede, the Netherlands, April 1998.

[11] T.A.M. Spil, H.J. van de Meeberg, and K. Sikkel (1999). The definition, selection and implementation of a new Hospital Information System to prepare the hospital for the electronic future: an example of project based education. 32th Annual Hawaii International Conference on Systems Sciences, Maui, HI.

[12] S. van der Honing (Ed.) (1995). Bedrijfsinformatietechnologie - onderwijs en onderzoek van een nieuwe opleiding aan de Universiteit Twente. [Business information technology, a new curriculum at the University of Twente; in Dutch] Faculty of Computer Science, University of Twente, Enschede, the Netherlands.

[13] E.E. Villarreal And D. Butler (1998). Giving Computer Science Students a Real-World Experience. $29^{\text {th }}$ SIGCSE symposium on Computer Science Education, 40-44. 